Cad. Est. Ling., Campinas, 53(1), Jan./Jun. 2011

\title{
SANÇÃO EM FONOAUDIOLOGIA: UM MODELO DE ORGANIZAÇÃO DOS SINTOMAS DE LINGUAGEM
}

\author{
GISELE GOUVÊA - PUC/SP* \\ REGINA MARIA AYRES DE CAMARGO FREIRE - PUC/SP** \\ CHRISTIAN INGO LENZ DUNKER - USP ${ }^{* * *}$
}

\begin{abstract}
RESUMO: Este artigo tem como objetivo apresentar o esboço de um modelo de organização dos sintomas em Fonoaudiologia, no quadro de uma hipótese de multiestratificação lingüística do inconsciente. Postulamos que os sintomas de linguagem pertencem a uma estrutura complexa de múltiplos estratos e interestratos sucessivos e superpostos que operam por contradição, oposição e diferença. Esta estrutura contém os intervalos espaciais, temporais e lógicos da linguagem, formando uma espécie de grade topológica dividida esquematicamente nos eixos horizontais - escrita, língua e fala - em relação aos eixos verticais - sujeito, Outro, metáfora e metonímia. Nossa hipótese é de há que um meta-procedimento, presente na clínica fonoaudiológica de modo constitutivo e característico, a que chamamos de sanção. Traduzir, transcrever e transliterar são formas diferentes de sancionar um sintoma de linguagem. Observamos que os sintomas de linguagem, embora emergindo predominantemente em um sobre os outros eixos, criam uma desarmonia de todo o sistema. Esta desarmonia é própria do funcionamento ordinário da linguagem. Os sintomas de linguagem são apenas exagerações ou restrições deste processo. Isto posto, isolamos o eixo da escrita como aquele que sustenta primariamente a tipologia proposta, ou seja, seria na relação sujeito falante-escrita que se constituiriam os tipos clínicos. Assim, se o sintoma de fala, por sua estrutura de sanção, responde à estratégia de tradução, teríamos um tipo clínico que levaria ao privilégio de uma estratégia no manejo terapêutico. Isto porque supusemos que a mudança no manejo da sanção impõe outros modos à estrutura de funcionamento da linguagem. O segundo tipo responderia à estratégia da transcrição e, o terceiro, à estratégia da transliteração. Concluímos que esta proposta está sujeita à validação, tanto pela experiência clínica como pela contra argumentação teórica. Mas nos parece um caminho promissor que poderá dotar a práxis fonoaudiológica de um estatuto clínico, tornando-a singular.
\end{abstract}

Palavras-chaves: Fonoaudiologia, Psicanálise e Linguística.

RESUMEN: Este artículo tiene como objetivo presentar el esbozo de un modelo de organización de los síntomas en la Fonoaudiologia, en virtud de una hipótesis de multiestratificación lingüística del inconsciente. Postulamos que los síntomas de la lengua pertenecen a una estructura compleja de estratos y ínter estratos sucesivos y superpuñados por contradicción, oposición y diferencia. Esta estructura contiene las intermisiones espaciales, temporales y lógicas del lenguaje, formando una especie de cuadrícula topológica dividida esquemáticamente en los ejes horizontales - escritura, lenguaje y el habla - y verticales - sujeto, Otro, metáfora y metonimia. Nuestra hipótesis es que existe una meta-procedimiento, presente en la clínica fonoaudiológica, en modo constitutivo y característico, a que nominamos sanción. Traducir, transcribir y transliterar son diferentes formas de sancionar a un síntoma de lenguaje. Hemos observado que los síntomas de lenguaje, todavía emergiendo predominantemente en uno sobre los demás ejes, crean una falta de armonía de todo el sistema. Esta falta de armonía es típica del funcionamiento ordinario del lenguaje. Los síntomas del lenguaje son sólo exageraciones o restricciones de este funcionamiento. Dado esto, aislamos el eje de la escritura como aquel que apoya primariamente la tipología propuesta, o sea, que en la relación sujeto hablante - escritura serian constituidos los tipos clínicos. Por lo tanto, si el síntoma de habla, por su estructura de sanción, responde a la estrategia de la traducción, tendríamos un tipo

* PUC-SP, São Paulo (SP), Brasil. gisele.gouvea@gmail.com

** PUC-SP, São Paiulo (SP), Brasil. freireregina@uol.com.br

*** USP-SP/Psicologia Clínica, São Paulo (SP), Brasil. chrisdunker@usp.br 
clínico que llevaría al privilegio de una determinada estrategia en la terapéutica. Esto porque supongamos que el manejo de la sanción impone otros modos a la estructura de funcionamiento del lenguaje. El segundo tipo responde a la estrategia de la trascripción y, el tercer, a la estrategia de transliteración. Llegamos a la conclusión de que esta propuesta parece un camino prometedor que podría dotar la praxis Fonoaudiológica de uno estatuto clínico singular.

Keywords: Speech, Language and Hearing Sciences, Psychoanalysis and Linguistics.

\section{INTRODUÇÃO}

A clínica fonoaudiológica pode ser definida como um campo na acepção matemática. Por campo entende-se a articulação entre o domínio e o contradomínio de uma função. Por função entende-se a relação co-variante entre elementos. O domínio corresponde ao conjunto de argumentos da função e o contradomínio aos seus valores. (Branquinho, 2006). Isto significa que as funções da clínica - semiologia, etiologia, diagnóstica e terapêutica - devem formar um conjunto a partir da articulação entre domínio e contradomínio. A heterogeneidade destas funções dificulta a elaboração consistente do campo dos sintomas de linguagem, uma vez que o valor de um mesmo signo clínico remete a diferentes argumentos e também a diferentes funções. Por exemplo, a mesma produção de linguagem pode, sob determinadas circunstâncias, ser etiologicamente considerada como efeito da perda progressiva de uma função lingüística (como se verifica em certas demências), como expressão de uma lesão cerebral (como se verifica em certas afasias) e como condicionada por certos limitantes no funcionamento dos órgãos fonoarticulatórios (como em certas disartrias ou dispraxias). Note-se que esta distribuição de sintomas, tendo em vista sua causa, não deve ser confundida com uma diferença de tipo semiológico, como a que encontramos, por exemplo, na distinção freudiana (Freud, 1891) entre: afasia verbal (perda de nexos associativos entre elementos da fala), afasia assimbólica (dissociação do nexo entre representação-palavra e representação-objeto) e afasia agnóstica (perda da capacidade de reconhecimento de objetos). Observe-se, ainda, que nem a distinção semiológica ou a distinção etiológica tomam em consideração a função intersubjetiva do sintoma, ou seja, sua dimensão pragmática na qual este se prende ao contradomínio da enunciação, à imprevisibilidade do ato de fala e seus efeitos de estranhamento. Ou seja, as três formas precedentes de sintomas não devem ser confundidas com a afasia simbólica (histeria), não porque possuam causalidades distintas ou pertençam a sistemas descritivos diversos, mas por serem funções clínicas diferentes do signo em questão.

$\mathrm{O}$ critério que se faz necessário estabelecer aqui é que um signo pertence ao campo do sintoma fonoaudiológico porque responde à intervenção fonoaudiológica. Esta divergência entre o estatuto epistemológico e o estatuto clínico do signo que define um sintoma vem sendo apontada por diversos pesquisadores em Fonoaudiologia. Ocorre que em qualquer função etiológica ou diagnóstica em que se encontre o sintoma de linguagem assim definido, não se pode ignorar o fato primário de que este, para tornar-se sintoma, deve ser sancionado. Não há sintoma fora da estrutura da clínica, o que não implica que não exista sofrimento, normalização ou mal estar na linguagem.

Este é um fato elementar, mas não exclusivo da clínica fonoaudiológica. O sintoma, antes de ser sancionado ou derrogado pelo especialista, passa por uma série de leituras 
e contra leituras preliminares. Pais, educadores, profissionais de saúde e virtualmente qualquer aparelho ideológico que possua autoridade sobre o uso da língua sanciona ou derroga seu emprego formal ou normativo, habilitando ou segregando o falante. Seguimos aqui a indicação de Jerusalinsky (2004) de que há uma operação de transformação do traço para o signo e que esta operação pode ser considerada como a inclusão em um discurso. Lembremos que há duas modalidades lógicas envolvidas na idéia de inclusão. De um lado, temos a inclusão como o elemento que pode ser contado como "um" dentro do conjunto. De outro, temos a inclusão como parte, na qual o elemento está "contido em", mas não "pertence a".

Apliquemos agora esta diferença entre fazer parte e fazer elemento, às operações que potencialmente incluem um sintoma em um discurso. Lembremos que esta distinção é capital no autor que funda a moderna filosofia da linguagem e que inspira este trabalho, a saber, Gotlob Frege ( 1892[1978]). Chegamos assim a duas dimensões de inclusão do sintoma:

(a) Como elemento discreto e acidental da fala. Elemento que pode ser contado em sua recorrência e reconhecido em cada reaparição, como um traço. Por exemplo, os distúrbios articulatórios, os distúrbios de leitura e escrita, o tatibitate dos atrasos de linguagem são definidos pela recorrência de determinados traços, todos eles incluídos como argumentos da mesma função lógica que define aquele sintoma particular em seus diferentes valores. A diferença na forma de contagem e reconhecimento do elemento, explica, por exemplo, a distinção proposta por alguns autores (Zorzi,1998; Oliveira e Oliveira, 2004) entre desvio fonético (quando há alteração orgânica) e desvio fonológico (quando não há alteração orgânica).

(b) Como parte constante e onipresente da fala. Parte que não pode ser contada em sua recorrência indiciada por traços constantes, mas que se exprime como um indiscernível na leitura do traço. Parte que não se define pela constância de seu significado patológico, mas pela variação de meios de linguagem ou pela alteração do sistema de escrita ${ }^{1}$ no qual ela se torna legível para o outro. As pausas, as gesticulações compensatórias, as autocorreções não são traços que remetem ao mesmo significado patológico ou à mesma função sintomática, mas alterações do plano de legibilidade do evento: como traço, signo, significante ou sintoma.

Podemos passar agora do plano lógico para o plano lingüístico de consideração da operação de inclusão do sintoma no discurso. Três operações deste tipo tem sido abordadas pelos teóricos da clínica: tradução, transcrição e transliteração (Alouch, 1994; Vorcaro; 1998 Vorcaro, 2004). A forma mais simples de inscrição está baseada na operação de tradução. Traduzir é passar de um significante a outro mantendo o mesmo significado tal como ocorre nas dislalias, quando o falante produz um som onde a língua exige outro. A estratégia tradutiva é característica dos aportes que procuram semiologicamente estabilizar a relação entre conceito e referente.

Consideremos agora a afasia assimbólica, na qual há ruptura do laço entre representação-objeto e representação-palavra. Sua apresentação clínica não é equivalente à da amnésia, como puro esquecimento. Há esquecimento, mas acompanhado do "saber que se esqueceu" e do reconhecimento, por exemplo, de que a produção substitutiva é incorreta ou discordante. Aqui não se trata de tradução, mas da passagem de um meio de

${ }^{1}$ Um sistema de escrita representa a ideografia primordial que reproduz o emprego fonético e simbólico, simultaneamente, dos elementos significantes. 
linguagem para outro. Esta operação é conhecida como transcrição, ou seja, a passagem de um tipo de signo (verbal, acústico, visual, mnemônico) para outro tipo de signo.

Ao lado da estratégia de tradução e de transcrição podemos isolar um terceiro tipo. Trata-se da passagem de um sistema de escrita para outro sistema de escrita. Por exemplo, um determinado caractere caligráfico pode ser lido em chinês como a expressão fonética mizu e em japonês como $s u$ - $i$, ambos referindo-se ao mesmo significado (água). São transcrições diferentes do mesmo grafismo (Vappereau, 2006). No entanto, quando passamos do chinês para o coreano ou para o português não estamos apenas traduzindo, mas também transliterando. Transliterar significa passar de um sistema de escrita para outro sistema de escrita. Por sistema de escrita entendemos as marcas e traços anteriores e condicionantes da emergência de significantes. Tais marcas são resíduos do encontro com o Outro e se inscrevem na corporeidade daquele que virá a ser um sujeito. Ao contrário do significante que presume diferença, negação e oposição; o traço presume identidade, rasura e continuidade. Assim as diferenças entre a voz soprosa e a áspera são diferenças não diacríticas, perceptíveis segundo um sistema de escrita que é o vocal. A tonicidade muscular e postural, os movimentos compensatórios da gagueira, as alterações rítmicas e melódicas da fala são exemplos de articulações de diferentes sistemas de escrita. Traduzir, transcrever e transliterar são formas de inscrever um ato de fala como produção discursiva e formação de linguagem. Neste trabalho, consideramos os sintomas de linguagem como impedimentos, exagerações, deslocamentos e facilitações dos processos de tradução, transcrição e transliteração. Eles tomam em consideração, de maneira distinta, a função de autoria, o efeito de sujeito e a posição de enunciação. A heterogeneidade destas funções lógico-lingüísticas associa-se com o modelo suposto por este trabalho para a aquisição de linguagem, a saber, que esta se dá por meio de deslocamentos entre a primeira posição (dominância da fala do outro), segunda posição (dominância no funcionamento da língua) e terceira posição (dominância da relação entre sujeito e sua própria fala), tal como postulado por Lemos (2002).

Chegamos assim à idéia de que a clínica fonoaudiológica precisa encontrar uma operação elementar que permita explicar sua eficácia e seus fracassos no quadro de uma hipótese de multiestratificação lingüística do inconsciente (Dunker, 1996). O objetivo do presente artigo é apresentar o esboço de um modelo de organização dos sintomas em Fonoaudiologia, tendo em vista esta multiestratificação. Para tanto, adotaremos o ponto de vista de que há uma ação que não só especifica o manejo do fonoaudiólogo no interior da clínica fonoaudiológica como a distingue das clínicas psicanalítica, psicológica ou médica. Trata-se de um metaprocedimento que chamaremos de sanção.

Devemos esclarecer que, em que pese a presença desta noção na psicanálise, nas ciências jurídicas e nas ciências da linguagem, o que pretendemos aqui é desenvolver um conceito fonoaudiológico de sanção, explorando sua homologia com os campos afins que alimentam extensionalmente esta noção.

\section{PARA INTRODUZIR O CONCEITO DE SANÇÃO EM FONOAUDIOLOGIA}

Postulamos que as práticas fonoaudiológicas, quaisquer que sejam, independentes de sua orientação teórica ou justificação epistemológica, utilizando ou não este conceito 10 
explicitamente, reúnem-se neste metaprocedimento clínico que é a sanção. Uma rápida inspeção histórica sobre o que define, de modo mais genérico e constante, a ação terapêutica do fonoaudiólogo, dificilmente deixará de verificar que seu fazer começa e muitas vezes termina no juízo diante da fala do paciente. Juízo cuja forma lógica é binária: "isto sim" ou "isto não". Expomo-nos assim a uma condição simples de refutabilidade. Basta um exemplo prático, que se reconheça como fonoaudiológico, e que prescinda deste gesto de sanção no trato com a linguagem dos pacientes, para que nossa hipótese seja contrariada. Há uma implicação lógica em curso aqui: não há clínica sem sintoma e não há sintoma sem reconhecimento de um signo como exceção. Um sintoma é um regime de exceção dentro da fala.

Argumentamos que a capacidade de reconhecer o acidente e corrigir-se ou, inversamente, de sancionar o ato, o sujeito e a lei (como ação de linguagem), seja pelo gesto positivo, seja pelo silêncio, ou ainda pela negação, é o fundamento da ação terapêutica fonoaudiológica.

Considerando a hipótese acima apresentada, para constituir o campo dos sintomas de linguagem, definindo suas regras de composição e suas estratégias de formação, seria preciso delinear as diferentes maneiras de considerar a sanção e sua incidência sobre um sujeito.

No campo clínico fonoaudiológico a sanção é determinada por sua múltipla inscrição clínica. A etiologia dos sintomas de linguagem deveria ser reconsiderada a partir da noção de estrutura, o que implica um tipo de causalidade específica, não linear, não mecânica, mas dependente da relação não inclusiva entre regra e excepcionalidade. Aqui o conceito de sanção precisa distinguir sua incidência diferencial como causa, motivo ou razão na ordem da produção de linguagem. A sobreposição de noções como determinação, causalidade e implicação lógica, contidas no conceito mais geral de estrutura, tem desviado a Fonoaudiologia das considerações etiológicas, o que contribui ainda mais para a reificação de sua técnica. Imaginar que a noção de etiologia prende-se apenas ao registro médico, e restringe-se ao tipo de casualidade que lhe é atinente, é um equívoco tão crasso quanto refutar o uso do conceito de semiologia, tal como postulou Saussure (2003[1916]), apenas porque a noção de semiologia é encontrada na Medicina. Seria preciso explicar de que forma a sanção induz efeitos de reversibilidade do sintoma de linguagem, à guisa de um caso modelo de como o mesmo procedimento pode agir sobre diferentes aspectos da fala.

A semiologia considerada do ponto de vista da sanção implica o levantamento topológico das marcas do sintoma nas cadeias da linguagem. Ou seja, neste caso o conceito de sanção desenvolve-se no quadro mais geral de uma teoria do reconhecimento e não de uma teoria do conhecimento.

A diagnóstica fonoaudiológica tem se valido da sanção na prática da distinção entre sintomas como vimos na introdução deste trabalho. As diferentes formas de inclusão discursiva do sintoma: pela medicina, pela psicologia, pela odontologia, pela pedagogia, pela psiquiatria podem ser redescritas em função de seus mecanismos de estratificação lingüística. É pela sanção tradutiva, transcritiva ou transliterativa que se operam distinções entre as patologias de linguagem.

Contudo, é na dimensão terapêutica fonoaudiológica que a sanção mostra-se um procedimento constitutivo. Neste caso o manejo da sanção determina a incidência sobre as 
causalidades como "perda", "desvio" ou "desorganização" da linguagem. Vê-se aqui que a reversibilidade ou mudança do sintoma e da relação do falante com sua fala dependem da operação de sanção. As curas fonoaudiológicas, tanto as falsamente bem sucedidas, segundo critérios objetivistas, quanto as verdadeiramente mal sucedidas, segundo critérios subjetivistas, podem ser classificadas segundo o lugar onde se instala o agente da sanção: paciente ou fonoaudiólogo, família ou médico, escola ou comunidade. Em outras palavras, se o sintoma de linguagem pode ser tratado e revertido por operações de sanção não será porque ele mesmo possui estrutura de sanção?

A essência do conceito jurídico de sanção assenta-se no pressuposto soberano da hierarquia estratificada do poder, enquanto sustentação da lei. Há duas importantes noções presumidas pela idéia de sanção:

(a) imputação, segundo a qual presume-se intencionalidade, consciência e autoria ao sujeito jurídico.

(b) causalidade, segundo a qual presume-se cadeias de atos e efeitos, de fatos e valores ou de condutas e conseqüências.

Podemos derivar implicações do campo jurídico ao campo lingüístico observando que há:

(a) o conceito de sanção $d a$ lei (como assunção da língua pelo falante).

(b) o conceito de sanção à lei (como submissão do falante às regras da linguagem).

(c) o conceito de sanção pela lei (como ato de reconhecimento da fala, da língua e da linguagem pelo outro).

Partimos da premissa de que os sintomas de linguagem articulam-se entre o domínio da estrutura e o contradomínio do funcionamento. O campo dos sintomas de linguagem corresponderia assim à reunião destes dois aspectos, que agora reencontramos nas duas primeiras acepções da noção de sanção: submissão às regras da linguagem (estrutura) e assunção da língua pelo falante (funcionamento). Ocorre que estes dois aspectos da linguagem são insuficientes para descrever a experiência da fala. É preciso acrescentar ainda a dimensão paradoxal do ato temporal ou do acontecimento individual da fala, como fala de alguém endereçada ao Outro. Falar não é simplesmente ser o agente ou usuário de uma língua, falar é também ser autor. Falar é aceitar e modificar uma regra, realizar o universal da linguagem no singular de um sujeito por meio do particular de uma língua.

Se a sanção se exerce na forma do juízo e se este juízo é deontológico, ou seja, atinente ao "dever ser" da fala e suas respectivas formas de negação, podemos agora extrair o quadro modal de suas variações possíveis, apoiando-nos no estudo que Greimas (Greimas e Courtés, 2008) realizou sobre o tema:

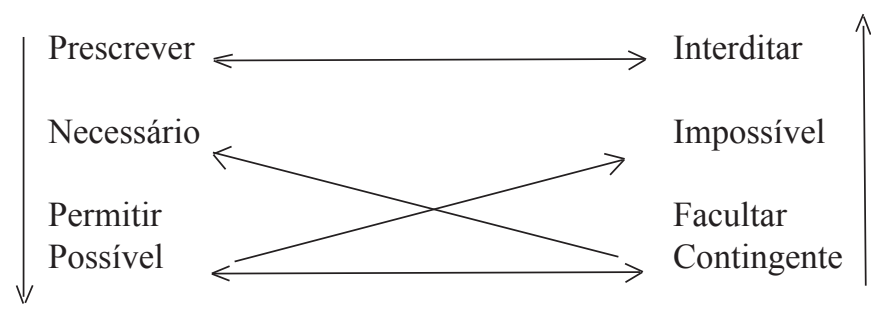


As quatro posições - contrárias, subalternas, opostas e contraditórias - replicam as relações lógicas do quadrado de Aristóteles. Observemos que o modelo presume que o ato, mais particularmente o de linguagem, é o lugar do surgimento das modalidades. Se este ato pode ser objeto de contradição à lei, e se prosseguimos na analogia entre ato de fala e lei de linguagem, podemos dizer que a sanção admite uma dupla incidência inicial:

(a) A que se deduz da contradição entre o necessário e o contingente, ou entre aquilo que é prescrito pela língua e aquilo que se verifica no ato. É o que ocorre nos atos de criação, seja neológica ou poética.

(b) A que se deduz da contradição entre o impossível e o possível, ou entre aquilo que é permitido ou interditado pelo Outro, seja como desvio, seja como atraso em relação à norma.

Observe-se que, em ambos os casos, a sanção é uma forma de reconhecimento que, ao derrogar o sentido do ato, acaba por instituir a realidade simbólica do ato como tal. Isso concorda com a acepção jurídica do termo que afirma que para haver sanção é necessário imputação e causalidade.

Permitir, facultar, interditar e prescrever são as quatro modalidades de sanção que encontramos extensamente na prática fonoaudiológica:

(1) A sanção como prescrição médico-jurídica que determina a individualização ou tipificação do uso da linguagem a partir de valores atrelados ao signo médico. Ou seja, a prevalência da premissa que limita a linguagem a descrições patognômonicas frente à primazia do orgânico, como se fosse possível isolar a fala e o falante em compartimentos neurológicos, acústicos, articulatórios, cognitivos, cerebrais. Aqui a sanção não faz relação com a estrutura da linguagem a que o sujeito submete-se, mas com a condição neuroanatomofisiológica do corpo em estados normais ou patológicos, sendo governada pela determinação da presença ou ausência de doença. Nesse sentido, a sanção assentase no papel normativo do fonoaudiólogo em homologar aquela fala como aceitável ou esperada para a idade cronológica, ou como patológica.

(2) A sanção como interdição do saber da linguagem que legitima a autoridade do falante sobre sua fala. Aqui encontramos a vertente pedagógica ou psicológica que utiliza o "saber" sobre o estado do corpo do sujeito, elegendo os "exercícios fonoarticulatórios" como terapêutica para o apagamento dos "erros". O jogo desta relação concentra-se no recorrente "saber" do fonoaudiólogo sobre o "não saber" do sujeito. Neste caso, a sanção não incide na função que vai do normal ao patológico, mas na função que vai do ato à potência, do fracasso ao sucesso, segundo o princípio do desempenho.

(3) A sanção como ratificação facultativa de prêmio ou confirmação moral. Aqui se dispõe sobre o cumprimento ou descumprimento das diretrizes do tratamento. Por exemplo, quando há o reconhecimento por parte do fonoaudiólogo da "boa" execução do exercício fonoarticulatório pelo paciente, elegem-se os "elogios e recompensas" ao final da sessão. Por outro lado, quando os exercícios fonoarticulatórios não são executados em casa, ou quando o sujeito não responde às demandas do fonoaudiólogo durante a sessão e este convoca os pais e a criança para uma conversa de cunho repreensivo, suprimindo a recompensa, há a sanção como castigo. Nesta via, presume-se a liberdade do falante para gerenciar seus desvios de linguagem. Vê-se aqui uma reciprocidade entre a estratégia baseada na facultatividade e a baseada na prescrição. 
(4) A sanção como permissão do uso da fala. Encontramos aqui todas as estratégias empenhadas em recuperar a autorização do falante sobre sua própria fala e reconhecer a validade intersubjetiva da variação de linguagem. São as correntes interacionistas ou dialéticas e, ainda, as linhagens inspiradas na psicanálise que têm insistido nas táticas de recuperação da fala pela via da re-subjetivação dos efeitos da língua, da escrita e da fala. Contudo, aqui também reencontramos a posição de autoridade sobre a linguagem que é, de certa forma, complementar nas estratégias de permissão e interdição.

\title{
3. A SANÇÃO COMO TRABALHO DO NEGATIVO: UMA HOMOLOGIA COM A PSICANÁLISE
}

Diz-se que conceitos são homólogos quando há correspondência ou equivalência entre eles em uma determinada série ou estrutura. Argumentamos que a noção de sanção, tanto em sua extração jurídica quanto em sua extração psicanalítica, mantém uma relação de homologia, e não de analogia, com a que se dá na prática fonoaudiológica. Ou seja, esta noção pertence a uma mesma série descritiva e semelhante em termos de origem (as ciências da linguagem), porém traz consigo funções diversas. O fonoaudiólogo não deveria julgar o uso da língua como o juiz julga uma causa, ou sancionar a mensagem que chega desde o inconsciente como o faz um psicanalista. $O$ ponto de inserção da homologia reside no fato de que tanto na psicanálise quanto na clínica fonoaudiológica a sanção é uma operação que articula os atos de reconhecimento intersubjetivos com o funcionamento estrutural da linguagem. Esta articulação se apresenta como comum desde que se considere a linguagem na chave de entendimento derivada do estruturalismo de Saussure e o sujeito na linhagem de investigação de tradição dialética de Hegel. Uma vez obedecidas estas duas condições, verifica-se que o ponto de homologia reside na hipótese de que a articulação entre uma e outra série obedece a modalidades distintas de negatividade. Tentaremos mostrar como este é o elemento comum entre as três acepções formativas do conceito de sanção que discutimos anteriormente. Para tanto recorremos a um breve exame da noção de sanção na obra de Lacan.

Lacan (1999[1956-57]), refere-se à noção de sanção, ao afirmar que:

\begin{abstract}
“(...) o que constitui a ênfase e o peso do fenômeno [do chiste] deve ser buscado em seu próprio centro, isto é, por um lado, no nível da conjunção dos significantes, e por outro, naquele - que já lhes indiquei - da sanção dada pelo Outro a essa criação. É o Outro que dá à criação significante um valor de significante em si, valor de significante em relação ao fenômeno da criação significante. É a sanção do Outro que distingue a tirada espirituosa do puro e simples fenômeno do sintoma, por exemplo" (LACAN, (1956-57), p. 49).
\end{abstract}

Embora a noção de Outro em Lacan tenha várias acepções, o que nos interessa é o fato de ser portadora de uma negatividade essencial que diverge quanto ao modo e ponto de incidência. A forma mais simples de indicar a ligação entre Outro e negatividade em Lacan é lembrar a noção fundamental de falo como significante da falta e da produção e estabilização da significação. Esta função articulatória entre falta e significação por um lado, e lei (impessoal) e autoridade (pessoal) por outro, se realiza, homologamente, na clínica 
fonoaudiológica, por meio da sanção. Contudo este regime de articulação da negatividade presume sempre uma espécie de duplicação entre a negatividade da linguagem (Outro, significante, signo, letra, traço) e a negatividade do sujeito: quer pela sua divisão (desejo, demanda, fantasia) quer pela sua abolição (afânise, angústia, alienação).

\footnotetext{
“(...) a função decisiva de minha própria resposta e que não é apenas, como se diz, a de ser aceita pelo sujeito como aprovação ou rejeição do seu discurso, mas realmente a de reconhecê-lo ou aboli-lo como sujeito" (Lacan (1998[1966]) Op. Cit., p.301).
}

Vê-se assim como a alternativa apresentada acima emprega a noção de sanção como articuladora entre a dialética do sujeito e do desejo e a estrutura da linguagem (conjunção significante). Ressaltemos que a sanção não é um conceito psicanalítico, em que pese o fato de ser empregada descritivamente por Lacan. Não há equivalência entre a sanção como prática fonoaudiológica e os procedimentos clínicos da psicanálise. Salientemos que o trecho aborda justamente a dimensão criativa da linguagem e que, tanto em psicanálise como homologamente na clínica fonoaudiológica, considera-se que o sintoma não é déficit de uma função genérica de expressão lingüística. Não se trata, contudo, de pensar que a sanção do Outro é neste caso o equivalente de uma ação de reconhecimento e validação consciencialista da criação presente no sintoma. A sanção não equivale ao gesto empírico de dizer que sim ou dizer que não, mesmo porque dizer que não é uma forma de sancionar a existência de algo, de validar a pertinência de uma demanda, de certificar a consistência de uma fantasia. A sanção se expressa sempre em uma modalidade de enunciação imaginária (prescrição, interdição, facultatividade, permissão) que se articula com uma dimensão simbólica (a Lei) e deixa como resíduo de sua operação um resto não integrável (o intraduzível, o não transcrito, o ainda não transliterado). A sanção é uma forma de reconhecimento, mas reconhecimento em vários níveis que se manifestam em co-presença, em alternância e em sucessão.

Há uma imagem que representa a indeterminação e a negatividade que queremos ressaltar como imanente à prática da sanção. Trata-se do antigo problema filosófico representado pela designação ostensiva, levantado por Santo Agostinho em relação ao caráter indicativo do signo. Quando se aponta o dedo em direção a uma parede o que queremos designar? A parede? A cor da parede? A ponta de nosso próprio dedo? A tela que não está mais pendurada ali? A mesma indeterminação acompanha a prática mais cotidiana do fonoaudiólogo ao tentar fazer reconhecer ao seu sujeito uma diferença vocálica, uma pausa, ou o valor oposicional de um fonema. Ao fazer o sujeito repetir, ao indicar para ele como se faz, ao recusar uma determinada produção, ao facultar a substituição de um termo por outro, ali está todo o problema relativo ao que está sendo reconhecido: a produção como um todo? O sentido da fala? A correção da língua? A intenção do sujeito?

O problema da designação ostensiva repercute na obra de Lacan levando-o a tentar encontrar para as propriedades formais das articulações entre os signos no sistema da linguagem, equivalentes em termos de propriedades intersubjetivas ou atos dialógicos de reconhecimento entre falantes. A introdução de referências aos sistemas de escrita (traço, marca, letra) representa uma solução para articular o regime da fala ao regime da língua, permanecendo no campo da linguagem e na função do sujeito. Desta maneira, as propriedades verificadas na função da conjunção dos significantes encontrariam uma 
GOUVÊA, FREIRE e DUNKER - Sanção em fonoaudiologia...

espécie de correlato ou contradomínio na função da sanção do Outro. De acordo com Lacan, (Lacan, 2002[1955], p. 63-64) o domínio do significante envolve duas propriedades:

(a) de ser composto por elementos articulados pela diferença, oposição e negação: "esses elementos (...) são os fonemas (...) o sistema sincrônico dos pareamentos diferenciais necessários ao discernimento dos vocábulos numa dada língua” (Idem, p. 504, negritos nossos).

(b) de se compor segundo as leis de uma ordem fechada, afirma-se a necessidade do substrato topológico da qual a expressão 'cadeia significante', que costumo dizer, fornece uma aproximação: anéis cujo colar se fecha no anel de um outro colar feito de anéis". (Idem,p. 505, negritos nossos).

Ora, estas duas vertentes da economia significante correspondem de forma homóloga aos dois aspectos que estamos levando em conta na organização do campo dos sintomas: a estrutura e o funcionamento estratificado da linguagem. Desta maneira todas as propriedades da topologia significante, a fala, a língua e a escrita mostram-se passíveis de afetação pela sanção.

A sanção do Outro implica um tipo de representação que não segue a regra mentalista da intencionalidade, mas a regra materialista da definição lacaniana do significante: um significante representa um sujeito para outro significante. Finalmente, mas não menos importante, a sanção do Outro implica a assunção pelo sujeito da função dêitica da linguagem, através da qual os pronomes, por exemplo, podem substituir-se ao falante e às posições do Outro, repetindo-se em diferenças intercambiáveis. Verifica-se em todas estas aproximações que o conceito fonoaudiológico de sanção e a noção lacaniana de sanção são homólogos principalmente por partilharem descritiva e teoricamente do trabalho da negatividade e por se originarem em um campo comum, a saber, a lingüística.

\section{A INSTÂNCIA DA SANÇÃO NAS PATOLOGIAS DE LINGUAGEM: ESBOÇO DE UM MODELO}

Gouvêa da Silva (2007) parte das noções de (língua), (fala), (sujeito) e (outro), já defendidas em vários trabalhos (Frazão, 1996; Freire e Cordeiro, 1999; Freire, 2000 e 2002; Azevedo e Freire, 2001; Faim, 2002; Salles, 2002; Rubino, 2003; Fonseca e Vieira, 2004; Arantes, 2005; Castellano e Freire, 2006; Oliveira, 2006; Fonseca e Vorcaro, 2006, Pollonio e Freire, 2009; entre outros) como estando na base de uma clínica fonoaudiológica que afirme a linguagem como seu objeto. Entende-se que, se a intervenção fonoaudiológica realiza diferentes modalidades de sanção e se os sintomas de linguagem são responsivos a tal procedimento lingüístico, é porque os sintomas de linguagem podem ser redescritos em termos covariantes e homogêneos à sanção. Ora, o primeiro problema aqui é identificar a sanção com a função metalingüística, ou seja, como se toda sanção se exercesse na forma de um comentário sobre o uso da linguagem. O uso da função metalingüística é apenas o caso mais genérico e acintoso da sanção. Coloca-se então como dificuldade entender como a sanção pode operar nos diferentes registros da linguagem.

Passemos agora ao modelo de organização dos sintomas de linguagem partindo de sua responsividade e reversibilidade às práticas de sanção. Lembremos que a indeterminação 
da sanção decorre tanto do caráter multiestratificado do funcionamento dos sintomas de linguagem quanto da dimensão intersubjetiva deste procedimento. Presumimos que a semiologia fonoaudiológica pode ser construída por meio de noções como a de cadeia de significantes. Demonstramos em outro lugar (Gouvêa da Silva, 2007) que os sintomas de linguagem pertencem a uma estrutura complexa de múltiplos estratos e interestratos sucessivos e superpostos que operam por contradição, oposição e diferença. Esta estrutura contém os intervalos espaciais, temporais e lógicos ${ }^{2}$ da linguagem, formando uma espécie de grade topológica dividida esquematicamente nos eixos vertical e horizontal:

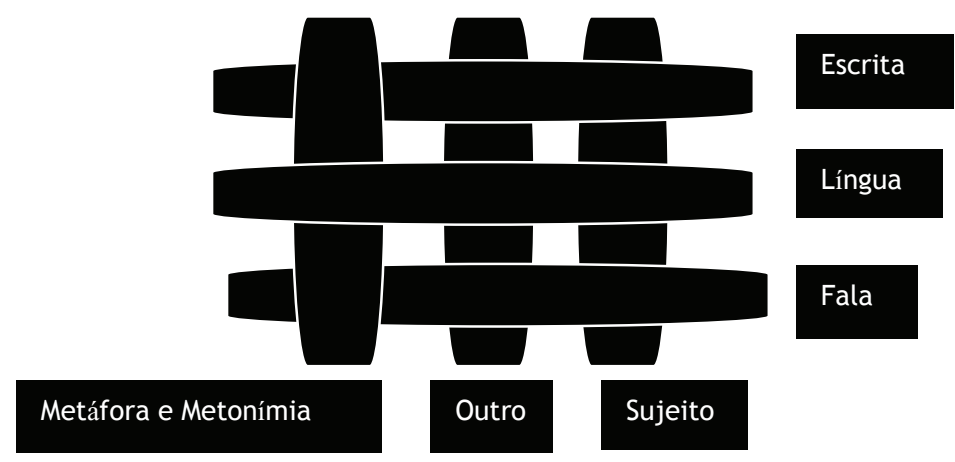

(Figura 1 - Grade Topológica dos Sintomas de Linguagem).

O estrato da escrita diz respeito à primazia do traço, isto é, da lógica de inscrição da letra significante no corpo que se caracteriza na alienação à sanção da fala do outro, fazendo com que o sujeito ocupe o lugar de ser falado pelo outro. O que se apresenta são fragmentos metonímicos de um corpo que é mais falado e olhado, incluído como parte em um discurso, do que subjetivado. Esta circulação da alienação segundo este tipo de sanção do Outro produz o efeito sintomático que chamamos de repetição primária. A repetição primária é tradução e assujeitamento à sanção do Outro em sua dimensão imaginária. A sanção de um traço como traço ocorre em intervenções como a correção, rasura ou apagamento do ato de fala na medida em que ele revela a emergência de um outro sistema em seu interior: o sistema da escrita. Aqui a sanção opera assinalando a contradição transliterativa, aquela relativa à passagem de um sistema de escrita para outro. Ou seja, a sanção terapêutica dissolve a sanção tradutiva que se implanta sobre o falante, incluindo-o no discurso.

O estrato da língua diz respeito à primazia do código pelo movimento de separação entre a fala do sujeito e a fala do outro. A lógica deste eixo opera pela sobreposição entre a divisão do sujeito e o significante. O efeito da sanção do Outro mostra-se aqui pelo que

${ }^{2}$ Derivado da noção de tempo enquanto um acontecimento sobre o outro. A interpelação do tempo é examinada pelos efeitos do hiato entre um acontecimento depois de outro acontecimento, isto é, das inscrições sintomáticas entre aquele que fala e escuta esta fala frente à sanção do Outro. A resposta se dá em vistas à quantidade de tempo despendida entre estes dois acontecimentos. A separação dos dois acontecimentos é um intervalo; a quantidade desse intervalo é a duração. 
chamamos de negação recíproca. Neste estrato há a sanção que reconhece e simboliza a indeterminação entre reconhecimento do sujeito ou reconhecimento do significante. Os movimentos de combinação metonímica e substituição metafórica são exemplos desta indeterminação: a metáfora do sintoma pode ser convertida em metonímia do desejo. Aqui o sintoma aparece como refratário à sanção do Outro. É a possibilidade de meta sanção, de sancionar a sanção recebida do outro ou de reconhecer o reconhecimento determinado pelo Outro. A sanção sobre o nível da língua ocorre em intervenções que modalizam o ato de fala em termos de alternatividade e interrogatividade, ou seja, sanciona-se o reconhecimento da língua (mas não a mensagem) ou sanciona-se a mensagem como mensagem (mas não o código). Aqui a sanção opera assinalando a contradição transcritiva, ou seja, relativa à passagem de um meio de linguagem para outro.

O estrato da fala concentra-se na lógica dialogal. Aqui a sanção incide sobre a reversibilidade entre quem fala e quem escuta. Os efeitos da sanção de uma fala/escuta sobre a outra implicam a sanção como reconhecimento no sujeito e no significante. A possibilidade de reformular e ressignificar a cadeia de fala depende de e exercita este estrato de linguagem. A negação por conservação é característica deste eixo. Aqui a sanção opera assinalando a contradição tradutiva, ou seja, relativa à passagem de um uso da língua para outro uso da língua. Este é o caso mais explícito de incidência da sanção metalingüística.

O paradoxo desta proposta supõe que a sanção, isto é, o estabelecimento do texto de lei que governa os falantes, é o elemento que articula a estrutura e o funcionamento da linguagem e, como tal, os efeitos da sanção de uma fala sobre a outra determinariam tanto a constituição como a reversão dos sintomas de linguagem. A sanção terapêutica dissolve a sanção anterior em vigor na relação do sujeito com a linguagem. Deste modo, a causalidade das patologias de linguagem e o direcionamento da terapêutica fazem remissão às formas de sanção entre um estrato e outro da linguagem bem como à relação de reconhecimento entre o sujeito e Outro.

Vejamos um exemplo. Uma criança de seis anos troca sistematicamente "sapo" por "chapo". Esta troca só se dá pelo efeito de sanção que não distingue os significantes em jogo. Há, portanto, uma tradução do significante "chapo" pelo significante "sapo" que mantém a identidade de seu significado. A sanção terapêutica deve agir negativamente, desfazendo a tradução, e afirmativamente, validando as oposições -/+ anterior e +/- alto, que distinguem "ch" - "s". Vê-se assim como a ação terapêutica incide em dois estratos diferentes, o da língua e o da escrita, produzindo efeitos no registro da fala. Decompondo a operação da sanção:
(a) Isto não para "chapo" (registro da língua)
(b) Isto sim para "s" (registro da escrita)
(c) Este fala + Isto fala (registro da fala)

Remanesce como questão examinar se de fato a posição clínica do fonoaudiólogo designa-se pela sua subsunção ao lugar do Outro, ao modo de um mestre da linguagem ou um mestre do discurso. 
Os efeitos desse paradoxo indiciam que as marcas do sintoma estão dispostas nos eixos horizontais - escrita, língua e fala - em relação aos eixos verticais - sujeito, Outro, metáfora e metonímia - e que a mudança no manejo da sanção impõe outros modos à estrutura de funcionamento da linguagem. Nosso modelo supõe que a sanção, isto é, o estabelecimento da contradição do texto, fala ou mensagem (ou da contradição entre estes) replica e articula a estrutura e o funcionamento da linguagem como tal. Esta hipótese está exposta à comprovação pela experiência.

Propomos a negatividade operada pela sanção em três estratos como o algoritmo do sintoma de linguagem:

(1)

$\frac{\mathbf{A}}{\$} \rightarrow \$[\mathrm{~A}, \exists] \rightarrow \$[\mathrm{~S} 1, \mathrm{~S} 2] \cdot[\exists]$

que deve ser lido respectivamente como três operações lógicas:

(1) No primeiro tempo, a sanção (aqui representada pelo cifrão) procede originariamente do Outro, determinando a posição do sujeito e do significante. A barra indica aqui reunião e intersecção entre o sujeito e o Outro, exprimindo o processo de entrada na linguagem e aquisição da fala.

(2) No segundo tempo, a sanção oscila entre o Outro e o sujeito. O colchete inclui dois elementos de um conjunto, ao modo de um par ordenado. Ele traduz a noção de contagem e de ordem necessárias para o surgimento da função de autoria.

(3) No terceiro tempo, a sanção integra a cadeia significante e o sujeito. Há agora dois colchetes, o que se refere ao par significante (contagem por elementos) e o que se refere ao sujeito (contagem como parte).

Considere-se que A (grande Outro) deve ser lido em três níveis distintos:

(a) como lugar de onde o sujeito recebe sua própria mensagem de maneira invertida, ou seja, como lugar de sanção como negação do sentido de produção da mensagem (inversão).

(b) como grupo de posições, dadas pelo par ordenado (S1, S2) [significante mestre e significante do saber], que estão expostas às montagens de implicação do sujeito, da metáfora e da metonímia.

(c) como espaço de multiplicação da diferença por repetição, como se verifica em um sistema de oposições entre traços constitutivos, ou marcas, de um sistema de escrita.

O campo dos sintomas de linguagem fica assim definido por estes três estratos, admitindo-se o sujeito como domínio e o Outro como contradomínio da função de linguagem. 


\section{FRAGMENTOS DE UM CASO CLÍNICO:}

Para mostrar o funcionamento, tanto dos sintomas como da sanção e seus efeitos, expõe-se o caso de um sujeito, o Sr. N., em uma cena em que a fonoaudióloga (F) e o Sr. N. conversam sobre um livro de animais ${ }^{3}$ :

(1) F.: Como chama esse passarinho ai?

(2) Sr.N.: Nu sei, é, num sei, como chama esse.

(3) F.: Aqui tá dizendo que chama pica-pau.

(4) Sr.N.: Isso, aquele que joga tó-tó-tó-tó, to-tó-tó-tó, é, passarinho, esse, (S.I.), ganta esse aqui.

A primeira questão é sobre a sanção à fala do Sr.N. realizada pela fonoaudióloga. Sua intervenção incidiu como um corte sobre a relação pergunta-resposta: "Como chama esse passarinho ai??", ou seja, uma sanção na linha da interrogatividade. Isso provoca no Sr.N. o transbordamento de um outro sintoma - anomia - em que o traço apaga a coisa, que é a recusa por abolição: "Nu sei, num sei, como chama esse". Um dos sintomas que se manifesta na fala do Sr. N. é o da ordem do juízo de atribuição - isso se chama X.

A fala da fonoaudióloga (1) incide, na fala do Sr.N.(2). Ela interdita a cadeia de substituição que, em (3), retorna no nível da cadeia da sintaxe e possibilita em (4) que o Sr.N. deslize pelas duas cadeias, a da sintaxe e a dos sentidos.

Observe-se o uso excessivo de dêiticos: - "Como chama esse passarinho aí?" e depois "Nu sei, é, num sei, como chama esse" - e nas outras cadeias que comparecem esse, aquilo, aqui, isso. A fonoaudióloga opera no mesmo eixo do sintoma do Sr.N., ou seja, em que ambos escancaram uma relação pautada pela designação ostensiva, numa insistência significante marcada pela indeterminação do designado.

Outro fragmento:

(4) Sr.N.: Isso, aquele que joga tó-tó-tó-tó, to-tó-tó-tó, é, passarinho, esse, (S.I.), ganta esse aqui.

(5) F.: Ele canta?

(6) Sr.N.: Hum?

(7) F: Ele canta?

(8) Sr.N.: Canta, fala, fala também, pequeno.

(9) F.: Ele canta?

(10) Sr.N.: Hum?

(11) F.: Ele canta?

(12) Sr.N.: Canta sim, pequeno esse aqui.

(13) F.: Pequeno?

(14) Sr.N. Ahn?

(15) F.: Ele canta pequeno, seu Nelson?

Este segmento mostra que a fonoaudióloga mantém-se presa à oposição fonemática do significante "ganta" - "canta" e, ao fazê-lo, aprisiona a mensagem em uma circularidade que não faz laço na fala do Sr.N, ou seja, não lhe permite levar o diálogo a outro lugar. Um bom exemplo de como o apelo à sanção metalingüística incide em um eixo equivocado. Seu sintoma está em outro lugar, em outro estrato. Além disso, a insistência do indeterminativo SP.

${ }^{3}$ Excertos extraídos do Banco de Dados de Fala e Escrita da linha Linguagem e Subjetividade da PUC- 
e das interjeições na fala da fonoaudióloga tem como efeito produções vazias como "Hum? Ahn?". São apelos tradutivos. A mensagem não se desenrola nem se inverte. A fonoaudióloga não lança sua fala para outro nível. A fonoaudióloga identifica-se ao tipo de sanção que constitui o sintoma do Sr. N. - traduzir, submeter-se, prescrever. Isso não permite que o paciente se posicione em outro estrato discursivo. Por essa via, a fala da fonoaudióloga e a do Sr. N. operam no mesmo estrato da linguagem. O reconhecimento comum inclui o sintoma em um discurso, que prossegue na cena terapêtica. Sugerimos assim uma regra de ação: não responder no mesmo estrato discursivo do paciente. Isso significa alterar o tipo de sanção em curso.

Um outro recorte:

(16) Sr.N.: Não, grande é o grande, mas é pequeno assim esse aqui ó esse aqui ó (aponta o picapau).

(17) F.: É o mesmo.

(18) Sr.N.: É, esse então, este aqui? (aponta o pica-pau).

(19) F.: Este passarinho aqui?

(20) Sr.N.: É passa, para, passarapa, para. Pau. É.

(21) F.: Ahn... pica-pau.

Aqui verificamos a emergência sintomática na fala do Sr. N. Em (16) ocorrem duas oposições cruzadas entre grande e pequeno. Um exemplo da oscilação entre negação em nível significante e negação em nível do sujeito. A fonoaudióloga observa que é preciso designar o que representa o "aqui ó" dissolvendo o dêitico por uma nomeação em (18) "É, esse então, este aqui? - da fala do Sr.N., mas só o faz um momento fora da cena, lugar que pode abrir os parênteses e designar o que seria aquele apontar do Sr.N. e rearranjar a sua posição.

Em (20) - "passa, para, passarapa, para. Pau.” o Sr. N. alinha as dimensões da sucessão sonora com a da substituição homofônica. O sintoma se apresenta na impossibilidade de alinhar as redes da sintaxe, justamente pelo fato de que as oposições sonoras e significantes estão aglutinadas - passarinho e pica-pau - numa espécie de homofonia sintática e semântica. Aqui falta o recurso ao sistema de escrita, ou uma sanção de tipo transliterativa.

Um quarto fragmento:

(22) F.: Então fala, este passarinho aqui. (aponta o pica-pau).

(23) Sr.N.: Ahn? Arapau, ara...

(24) F.: Pica-pau.

(25) Sr.N.: Pi, picãu, pi, picáu. Pi, pi, picau.

(26) F.: Pica...

(27) Sr.N.: Cau...

(28) F.: Pau.

Assim, em (23) - "Arapau, ara"; em (25) - "Pi, picãu, pi, picáu. Pi, pi, picau” e, em (27) - "Cau", a sucessão sonora e a decomposição significante da fala do Sr.N. fazem com que a fonoaudióloga sancione de maneira a reconhecer uma cadeia significante nesta fala. No entanto, a fala da fonoaudióloga opera no mesmo eixo da fala do Sr. N., qual seja: o da sucessão sonora e da decomposição significante, homofonia significante, mensagem 
simétrica, sem reversibilidade código-mensagem. Aqui falta a possibilidade de inversão da mensagem pelo Outro, o que se verificaria pelo aumento do nível de ambigüação intencional. Por outro lado podemos verificar como a incidência sintomática neste caso é cobrir uma desarticulação na dimensão dialogal e, por isso, os sintomas aparecem nos estratos da escrita e da língua.

\section{CONCLUSÃ̃o}

O objetivo do presente artigo foi apresentar um modelo para organização dos sintomas em Fonoaudiologia, tendo em vista a perspectiva diferencial que o fonoaudiólogo toma diante do sintoma, reconhecida como o metaprocedimento da sanção. Argumentamos que a capacidade de reconhecer diferencialmente o acidente, a irregularidade ou a falha na linguagem implica a adoção tácita ou explícita de uma teoria de linguagem. O fundamento da ação terapêutica fonoaudiológica consiste em sancionar de forma pluriunívoca as heterogeneidades da linguagem. Ou seja, em um único ato de sanção realizam-se múltiplas incidências: na fala, na língua e na escrita; no sujeito, no Outro e na relação intersubjetiva. Sancionar é, ao mesmo tempo, validar ou vetar um ato e reconhecer ou desconhecer um sujeito. Seja pelo gesto afirmativo, seja pela ilação negativa, seja pelo silêncio ou pela interrogatividade verifica-se uma pluralidade de efeitos decorrentes de um mesmo ato. Se a intervenção fonoaudiológica baseada na forma genérica da sanção realiza diferentes modalizações do sintoma e se os sintomas de linguagem são responsivos a tal procedimento lingüístico é porque estes podem ser redescritos em termos covariantes e homogêneos à sanção. E, ainda, se os sintomas fonoaudiológicos são reversíveis por operações de linguagem (como as envolvidas na sanção), é porque, necessariamente, eles mesmos possuem estrutura de linguagem.

Isso nos fez propor um modelo operativo e ampliado do que entendemos por estrutura de linguagem. Todavia, ao contrário da abordagem convencionalmente em uso nas ciências da linguagem que pensa a estrutura em termos descritivos, em nosso modelo tentamos apresentá-la privilegiando sua transformatividade. Ou seja, enfatizamos as operações compatíveis com o procedimento terapêutico que define o campo da Fonoaudiologia.

Traduzir, transcrever e transliterar são formas diferentes de validar ou reconhecer um ato de fala ou uma produção discursiva que tomam em consideração, de maneira distinta, a função de autoria, o efeito de sujeito ou a posição de enunciação. São modalidades diferentes de sancionar um sintoma de linguagem, ou seja, de inscrevê-lo como tal. Afirmamos que os sintomas de linguagem pertencem a uma estrutura complexa de estratos e interestratos sucessivos e superpostos que operam por contradição, oposição e diferença, formando uma espécie de grade topológica dividida esquematicamente nos eixos horizontais - escrita, língua e fala - em relação aos eixos verticais - sujeito, Outro, metáfora e metonímia.

Propusemos que essas modalidades ou estratégias não apenas formalizem a prática clínica como permitam a constituição de uma tipologia clínica que possa subsidiar a formação de uma diagnóstica propriamente fonoaudiológica. Ou seja, de acordo com a 
resposta do sintoma à ação fonoaudiológica podemos redescrevê-lo e incluí-lo no discurso que constitui este campo.

Observamos que os sintomas de linguagem, embora emergindo predominantemente em um sobre os outros eixos, provocam uma desarmonia em todo o sistema. Esta desarmonia é própria do funcionamento ordinário da linguagem. Os sintomas de linguagem são apenas exagerações ou restrições destes processos. Isto posto, isolamos o eixo da escrita como aquele que sustenta primariamente a tipologia proposta, ou seja, seria na relação sujeito falante-escrita que se constituiriam os tipos clínicos. O eixo da escrita é a marca, o traço primeiro (choro, balbucio, grito) do bebê, que ao ser sancionado pela mãe como demanda em um primeiro momento e, ao mesmo tempo, por ela reescrito como fala, é rasurado e substituído pelo significante. Se não o for, poderá aí se inscrever um sintoma de base. Assim, esta sanção primitiva seria o princípio da emergência de um falante ou de um tipo clínico, como os chamados retardos de linguagem.

Assim, se o sintoma de fala, por sua estrutura de sanção, responde à estratégia de tradução, teríamos um tipo clínico que, pelo discorrido, levaria ao privilégio de uma certa estratégia no manejo terapêutico. O segundo tipo, seguindo o mesmo raciocínio, responderia à estratégia da transcrição e, o terceiro, à estratégia da transliteração.

Por outro lado, afirmamos que uma ação sobre um eixo provoca transformações nos outros eixos. O princípio geral da ação clínica entre estratos pode ser vislumbrado em uma situação clínica em que um pré-adolescente com gagueira, tem o ritmo de sua fala alterado por um fazer do fonoaudiólogo em que este o convida a ler um trecho de um livro, acompanhando seu dedo que sublinha o texto, em ritmo mais lento. Sua fala altera-se como efeito dessa ação de escutar o outro e escutar-se de uma outra posição. Mas também a sua postura corporal, marcada por um tronco curvado para frente, por um olhar voltado para o chão, é transformada.

Concluímos que esta proposta nos parece um caminho promissor que poderá contribuir para consolidar o estatuto clínico singular da práxis fonoaudiológica.

\section{REFERÊNCIAS BIBLIOGRÁFICAS}

ALOUCH, J. (2005). Letra a Letra: transcrever, traduzir, transliterar. Companhia de Freud, Rio de Janeiro.

ARANTES, L. (2005). Sobre a instância diagnóstica na clínica de linguagem. In: Maria Francisca Lier-de-Vitto e Lúcia Arantes.(orgs.). Aquisição, Patologias e Clínica de Linguagem. Editora PUCSP,Educ: p. 315-330.

AZEVEDO, N.P.; FREIRE, R.M. (2001). Trajetórias de silenciamento e aprisionamento na língua: o sujeito, a gagueira e o Outro. In: Silvia Friedman e Maria Claudia Cunha(orgs.): Gagueira e Subjetividade. Porto Alegre: Artmed: p. 145-160.

BRANQUINHO, J. et alli - (2006). Enciclopédia de Termos Lógico-Filosóficos. Martins Fontes, São Paulo.

CASTELlANO, G.B e FREIRE, R.M. (2006). Análise de discurso de sujeitos disfônicos, Revista da Sociedade Brasileira de Fonoaudiologia, 11(1): p. 43-51.

DE LEMOS, C.T.G. (2002). Das vicissitudes da fala da criança e de sua investigação. Cadernos de Estudos Lingüísticos (42): 41-69, Jan./Jun. 
GOUVÊA, FREIRE e DUNKER - Sanção em fonoaudiologia...

DUNKER, C.I.L. (1996). Tempo e Linguagem na Psicose da Criança. Tese de Doutorado, Instituto de Psicologia da USP.

FAIM, M.G.T.C. (2002). Clínica Fonoaudiológica: uma discussão sobre a terapêutica dos desvios de linguagem. Dissertação (Mestrado em Fonoaudiologia) - Pontifícia Universidade Católica de São Paulo.

FONSECA, S.C.; VIEIRA, C. (2004). A afasia e o problema da convergência entre teoria e abordagens clínicas. Revista Distúrbios da Comunicação. Vol.16, nº1: p. 101-106.

FONSECA, S.C.; VORCARO, A. (2005). O atendimento fonoaudiológico e psicanalítico de um sujeito afásico”. In: Maria Francisca Lier-de-Vitto e Lúcia Arantes.(orgs.). Aquisição, Patologias e Clínica de Linguagem. Educ-Fapesp, p. 413-441.

FRAZÃO, Y.S. (1996). Paralisia Cerebral na clínica Fonoaudiológica: primeiras questões sobre linguagem. Dissertação (Mestrado em Fonoaudiologia) - Pontifícia Universidade Católica de São Paulo.

FREIRE, R. M.A. C.; CORDEIRO, D. T. (1999). Patologia de Linguagem: Uma Nosologia. Caderno de Resumos do Congresso Nacional da Abralin, UFSC Florianópolis,Santa Catarina: p. 190-190.

FREIRE, R. M.A.C. (2000). O diagnóstico nas alterações da linguagem infantil, Revista Distúrbios da Comunicação: Vol.12, nº1:107:116 . (2002). A Fundação da Clínica Fonoaudiológica. In: Congresso Brasileiro de Fonoaudiologia: (inédito).

FREGE, G. (1892). Sobre sentido e referência. In: Lógica e Filosofia da Linguagem, Cultrix, São Paulo, 1978.

FREUD, S. (1988) [1892]. Da Interpretação das Afasias. Edições 70, (1973) [1891]:72. Carta 52. In: Obras Completas Sigmund Freud, V-II. Amorrortu, Buenos Aires.

GOUVÊA DA SILVA, G. (2007). Por uma multiestratificação estrutural dos sintomas de linguagem. Dissertação (Mestrado em Fonoaudiologia) - Pontifícia Universidade Católica de São Paulo.

GREIMAS, A.J. e COURTÉS J. (2008). Dicionário de Semiótica, Editora Contexto, São Paulo.

JERUSALINSKY, A. (2008). Saber Falar - Como se adquire a lingua? Vozes, Rio de Janeiro. . (2004). A cura e o discurso. In: Quem Fala na Língua - sobre as psicopatologias da fala. Ágalma, Rio de Janeiro, p. 46-47.

LACAN, J. (2002[1955]). O seminário, Livro 3: As Psicoses. Trad. MD Magno. Rio de Janeiro: Jorge Zahar Editor.

. (1999[1956-57]. O seminário, Livro 5: As formações do Inconsciente”. Trad. MD Magno. Rio de Janeiro: Jorge Zahar Editor.

. (1998[1966]) Subversão do Sujeito e Dialética do Desejo no Inconsciente Freudiano. In: Escritos. Rio de Janeiro: Jorge Zahar Editor.

OLIVEIRA, J.T.N., OLIVEIRA Z.S.B. (2004). Desvio fonético X desvio fonológico: algumas considerações. J Bras Fonoaudiol. 5(20): p. 172-6.

OLIVEIRA, M.T. (2006). Reflexões sobre as falas ecolálicas e a interpretação fonoaudiológica a partir da discussão de dois casos de psicose infantil. Revista Distúrbios da Comunicação, São Paulo, 18 (3): p. 335-344.

POLLONIO, C. F. E FREIRE, R. M. (2008). O brincar na clínica fonoaudiológica. Revista Distúrbios da Comunicação: $19, \mathrm{n}^{\circ} 1$. 
RUBINO, R. (2003). - Atraso de linguagem e estruturação subjetiva: questões sobre a relação entre a clínica fonoaudiológica e a clínica psicanalítica. Revista Distúrbios da Comunicação. Vol.15, $\mathrm{n}^{\circ} 1$.

RUBINO, R. E FONSECA, S.C. (1998) Sobre o normal e o patológico na linguagem: algumas questões. Texto inédito, PUC-SP.

SALLES, F.B.C. (2002). "Semiologia em Fonoaudiologia: a subversão do conceito de doença". Dissertação (Mestrado em Fonoaudiologia) - Pontifícia Universidade Católica de São Paulo.

SAUSSURE, F. (2003[1916]). Curso de linguística geral. 25 ed. São Paulo: Cultrix.

VORCARO, A.M.R. (1998). Le statut de la donnée linguistique comme charnière des approches théoriques et cliniques, apresentado no $6^{\text {th }}$. International Pragmatics Conference, em Reims, França. (2004). A Criança na Clínica Psicanalítica. Companhia de Freud, Rio de Janeiro.

VAPPEREAU, J.M. (1997). Nudo - La teoria del nudo esbozada por J. Lacan. Kliné, Buenos Aires, 2006: II.

ZORZI J.L. (1998). Diferenciando as alterações da fala e da linguagem. In: Marchesan IQ. Fundamentos em fonoaudiologia: aspectos clínicos da motricidade oral. Rio de Janeiro: Guanabara Koogan; p. 59-74. 